\title{
Gilbert-Rutkow Mesh Plug Repair of Inguinal Hernia: A Teaching Hospital Based Study
}

\author{
Kamta Prasad Gupta ${ }^{1}$, Dinesh Pratap Singh ${ }^{2}$, Hanif ${ }^{3}$, Shahnawaz ${ }^{3}$ \\ ${ }^{1}$ Assistant Professor, Department of Surgery, VarunArjun Medical College \& Rohilkhand Hospital, Banthra, Shahjahanpur, Uttar Pradesh, India, ${ }^{2}$ Associate \\ Professor, Department of Surgery, Varun Arjun Medical College \& Rohilkhand Hospital, Banthra Shahiahanpur, Uttar Pradesh, India, ${ }^{3}$ Senior Resident, \\ Department of Surgery, Varun Arjun Medical College \& Rohilkhand Hospital, Banthra, Shahjahanpur, Uttar Pradesh, India.
}

\section{Abstract}

Background: A hernia is defined as an abnormal protrusion of a viscus or a part of it, through the wall that contains it but without a breach in the body surface. By far the commonest variety of hernia is the protrusion of abdominal wall. Inguinal hernia most probably has been a disease ever since mankind existed.Subjects and Methods:This study was conducted to compare, three different techniques of Rutkow-Robbins Repair (Group-A), Gilbert double Repair (Group-B) and Lichtenstein operation (Group-C).Results:In this study, out of total 95 patients, 60 $(63.1 \%)$ patients were having right indirect inguinal hernia, $30(31.6 \%)$ patients were having left indirect inguinal hernias and 10 (10.5\%) patients were having bilateral inguinal hernias. From the above data it is clearly shown that there is much higher incidence of right sided indirect inguinal hernias as compared to the left sided indirect inguinal hernias and bilateral inguinal hernias. Conclusion: Lichtenstein technique is recognized as the most advantageous method in inguinal hernia repairs.

Keywords: Rutkow-Robbins Repair, Gilbert double Repair and Lichtenstein operation.

Corresponding Author:Dr. Dinesh Pratap Singh, Associate Professor, Department of Surgery, VarunArjun Medical College \&Rohilkhand Hospital, Banthra, Shahjahanpur, Uttar Pradesh, India.

Received: June 2019

Accepted: June 2019

\section{Introduction}

"No disease of the human body, belonging to the province of the surgeon, requires in its treatment, a better combination of accurate, anatomical knowledge with surgical skill than hernia in all its varieties"

-Sir Astley Cooper A hernia is defined as an abnormal protrusion of a viscus or a part of it, through the wall that contains it but without a breach in the body surface. By far the commonest variety of hernia is the protrusion of abdominal wall. Inguinal hernia most probably has been a disease ever since mankind existed. ${ }^{[1]}$ In humans, the upright posture causes the gravitational stress to pass down to the lower abdominal wall. Furthermore, the inguinal canal is directed downwards, and the intraabdominal contents pressing on its internal opening tends to dilate it and cause the loops of bowel to enter the canal. ${ }^{[2]}$ Approximately 12,000 hernia operations are performed in Finland, whereas 80,000 and 800,000 are conducted in England and USA, respectively. Although the exact prevalence is still unknown, its prevalence among men is around 4-7\%. ${ }^{[3]}$ As people get older, hernia incidence, strangulation frequency, and length of hospital stay exhibit rises. ${ }^{[4]}$ While the underlying etiology has not been understood yet, processusvaginalis patency, genetic inheritance, and erect posture are held responsible for its development. ${ }^{[5]}$ Currently, hernia is treated with surgery. Hernia surgeries comprise $10-15 \%$ of all general surgery procedures. ${ }^{[6]}$ In terms of recurrence and complication rates, tension-free repairs are the most commonly preferred operative techniques. Lichtenstein method and it's modifications such as Gilbert and Rutkow-Robbins are known to be tension-free anterior approaches which have been found to produce considerably low recurrence and complication rates. ${ }^{[7,8]}$ Moreover, the fact that those operations can also be performed under local anesthesia instead of general or spinal anesthesia provides yet another advantage. Our aim was to be compare the Lichtenstein technique with Rutkow-Robbins and Gilbert double layer techniques in inguinal hernia repair with regard to operation length, postoperative pain, early and late complications, recurrence rates, length of hospital stay, recurrence rates and time required to return to work.

\section{Subjects and Methods}

The present study has been conducted in the Department of Surgery, VarunArjun Medical College \&Rohilkhand Hospital, Banthra, Shahjahanpur, Uttar Pradesh, India, on patients of Inguinal hernia, who were admitted and undgergone hernia repair in VarunArjun Medical College \&Rohilkhand Hospital, From January 2018 to May 2019 (Prospective study) among various types of cases of inguinal 
hernia including direct and indirect, reducible or irrecucible, cases of obstructed or strangulated hernia and recurrent hernia were excluded to avoid the probable confounding interference with result of this study. In our study of prosthetic repair technique, Rutkow-Robbins Repair (Group A), Gilbert double Repair (Group B) and Lichtenstein operation (Group C). In the prospective study a total of 95 cases were included with 30 cases in group A, 15 cases in group $\mathrm{B}$, and 50 cases in group $\mathrm{C}$ respectively. All cases were followed up for a period of one and half years.

\section{Result \& Discussion}

The present study was conducted on 95 patients admitted with inguinal hernias, at Department of Surgery, VarunArjun Medical College \&Rohilkhand Hospital, Banthra, Shahjahanpur, Uttar Pradesh, India. This study was conducted to compare, three different techniques of RutkowRobbins Repair (Group-A), Gilbert double Repair (GroupB) and Lichtenstein operation (Group-C). The study was carried out on 95 patients. All patients included in this study were male. The youngest patient was 17 years old and the oldest was 75 years old [Table 1]. In this study conducted on four groups and the data collected above reveals that the maximum number of patients were operated in the age group 56-65 years. Minimum age 17 years, maximum age 75 years mean age 51.5 years.

\begin{tabular}{l}
\hline Table 1: Shows the age distribution of all Groups \\
\begin{tabular}{|l|c|c|c|c|c|c|}
\hline \multirow{2}{*}{$\begin{array}{l}\text { Age } \\
\text { group }\end{array}$} & \multicolumn{2}{|c|}{ Group A } & \multicolumn{2}{c|}{ Group B } & \multicolumn{2}{c|}{ Group C } \\
\cline { 2 - 7 } & $\begin{array}{c}\text { No. of } \\
\text { cases }\end{array}$ & $\%$ & $\begin{array}{c}\text { No. of } \\
\text { cases }\end{array}$ & $\%$ & $\begin{array}{c}\text { No. of } \\
\text { cases }\end{array}$ & $\%$ \\
\hline $16-25$ & 1 & 3.3 & 0 & 0 & 2 & 3 \\
\hline $26-35$ & 2 & 6.6 & 1 & 6.6 & 3 & 6 \\
\hline $36-45$ & 12 & 40 & 2 & 13.3 & 6 & 20 \\
\hline $46-55$ & 13 & 43 & 4 & 26.6 & 16 & 33 \\
\hline $56-65$ & 2 & 6.6 & 6 & 40 & 18 & 26 \\
\hline $66-75$ & 0 & 0 & 2 & 13.3 & 5 & 7 \\
\hline Total & 30 & & 15 & & 50 & 95 \\
\hline
\end{tabular}
\end{tabular}

Table 2: Shows the side of hernia

\begin{tabular}{|l|l|l|l|l|l|l|}
\hline \multirow{2}{*}{ Sides } & \multicolumn{2}{|l|}{ Group A } & \multicolumn{2}{l|}{ Group B } & \multicolumn{2}{l|}{ Group C } \\
\cline { 2 - 7 } & $\begin{array}{l}\text { No. of } \\
\text { cases }\end{array}$ & $\mathbf{\%}$ & $\begin{array}{l}\text { No. of } \\
\text { cases }\end{array}$ & $\%$ & $\begin{array}{l}\text { No. of } \\
\text { cases }\end{array}$ & \% \\
\hline Right side & 20 & 66.7 & 10 & 66.7 & 30 & 60 \\
\hline Left side & 8 & 26.6 & 2 & 13.3 & 15 & 30 \\
\hline Bilateral & 2 & 6.7 & 3 & 20 & 5 & 10 \\
\hline Total & 30 & & 15 & & 50 & 95 \\
\hline
\end{tabular}

In this study, out of total 95 patients, $60(63.1 \%)$ patients were having right indirect inguinal hernia, 30 (31.6\%) patients were having left indirect inguinal hernias and 10 $(10.5 \%)$ patients were having bilateral inguinal hernias. From the above data it is clearly shown that there is much higher incidence of right sided indirect inguinal hernias as compared to the left sided indirect inguinal hernias and bilateral inguinal hernias.

Table 3: Shows the Anaesthesia used during operation.

\begin{tabular}{|l|l|l|l|}
\hline Sr. No. & Anaesthesia & No. of cases & \% \\
\hline 1. & General & 4 & 4.2 \\
\hline 2. & Spinal/Epidural & 81 & 85.3 \\
\hline 3. & Local & 10 & 10.5 \\
\hline
\end{tabular}

[Table 3] Shows the $4(4.2 \%)$ were operated on under local anesthesia, $81(85.3 \%)$ and $10(10.5 \%)$ of them were operated on under spinal anesthesia and general anesthesia, respectively.

Table 4: Demographics and clinical charateristics of patients

\begin{tabular}{|l|l|l|l|l|}
\hline Variables & Group A & Group B & Group C & P value \\
\hline Operative time in & $52.4 \pm$ & $60.7 \pm$ & $52.9 \pm$ & 0.001 \\
minutes & 10.2 & 12.2 & 10.6 & \\
\hline $\begin{array}{l}\text { Hospitalization Time } \\
\text { in days }\end{array}$ & $2.3 \pm 0.67$ & $2.06 \pm$ & $2.09 \pm 0.5$ & 0.62 \\
\hline $\begin{array}{l}\text { Return to Time in } \\
\text { days }\end{array}$ & $25.4 \pm$ & $24.6 \pm$ & $23.2 \pm 2.6$ & 0.36 \\
\hline
\end{tabular}

[Table 4] Shows the none of the three methods showed a statistically significant difference regarding Hospitalization time and return to normal activities $(\mathrm{p}>0.05)$. There was a statistically significant difference between the groups regarding operation lengths $(\mathrm{p}<0.05)$.

[Table5] Shows the drain was used in $12(12.6 \%)$ patients in total and there was no statistically significant difference between the groups $(\mathrm{p}=0.46)$. Similarly no significant difference was noted between the groups on the basis of early or late complications ( $\mathrm{p}>0.05)$.

Table 5: Shows the post operative systemic complication.

\begin{tabular}{|l|l|l|l|l|}
\hline Variables & Group A & Group B & Group C & P value \\
\hline Males & 30 & 15 & 50 & \\
\hline $\begin{array}{l}\text { Early } \\
\text { Complications }\end{array}$ & $4(13.3 \%)$ & $2(13.3 \%)$ & $1(2 \%)$ & 0.21 \\
\hline $\begin{array}{l}\text { Late } \\
\text { Complications }\end{array}$ & $3(10 \%)$ & $4(26.7 \%)$ & $4(8 \%)$ & 0.63 \\
\hline Drain & $2(6.7 \%)$ & $3(20 \%)$ & $7(14 \%)$ & 0.46 \\
\hline
\end{tabular}

\begin{tabular}{|c|c|c|c|c|}
\hline \multicolumn{5}{|c|}{ Table 6: Shows the Recurrence rate } \\
\hline $\begin{array}{l}\text { Study } \\
\text { group }\end{array}$ & $\begin{array}{c}\text { No. of } \\
\text { patients in } \\
\text { follow up }\end{array}$ & $\begin{array}{l}\text { Relapse in } \\
\text { first } 6 \\
\text { month }\end{array}$ & $\begin{array}{l}\text { Relapse in } \\
\text { next } 1 \text { year }\end{array}$ & $\begin{array}{c}\text { Total } \\
\text { relapse }\end{array}$ \\
\hline Group A & 30 & 0 & 0 & 0 \\
\hline Group B & 15 & 0 & 0 & 0 \\
\hline Group C & 50 & 2 & 2 & 4 \\
\hline Total & 95 & 2 & 2 & 4 \\
\hline
\end{tabular}

Hernia repair is one of the most common surgical procedures performed worldwide. Improvements in surgical technique, together with the development of new prosthetic materials and a better understanding of how to use them, have significantly improved outcomes for many patients. These improvements have occurred most notably in centres specializing in hernia surgery, with some institutions reporting failure rates of less than $1 \%$. In contrast, failure rates for general surgeons, who perform most hernia repairs, remain significantly higher. Success of groin hernia repair is measured primarily by the permanence of the operation, fewest complications, minimal costs, and earliest return to normal activities. This success depends largely on the surgeon's understanding of the anatomy and physiology of the surgical area as well as knowledge of how to use most effectively the currently available techniques and materials. ${ }^{[9]}$ Inguinal hernia operations are still one of the most commonly encountered procedures in the lifetime of a general surgeon. While it is seen frequently, it is generally considered as a simple operation, but its anatomical planes 
are complicated. ${ }^{[10]}$ Although surgical treatment dates back to considerably old times, modern surgical treatment is recognized to begin with Bassini. ${ }^{[1]}$ In hernia surgery, the best indicator of the success of the operation is the recurrence which is totally based on objective criteria. While recurrence rates in tension operations of inguinal hernia vary depending on the applied method, it is reported to be about $5-10 \%$ among primary cases and $5-30 \%$ in cases of recurrence. $^{[12-14]}$ Currently, the success of Shouldice operation, which has been studied on large series and has become a gold standard with low recurrence rates, cannot be repeated universally. ${ }^{[15]}$ The common target in tension-free inguinal hernia repairs is to apply a totally tension-free support with a reliable prosthetic material implantation and to achieve long-term reinforcement of posterior wall of inguinal hernia or possible hernia sites. Currently, particularly the recurrences at early period (first 2 years) are recognized to arise from the tension of the suture line. First, physicians tried to use relaxing incision, but then it was found to have no effect over the problem. The idea to totally and permanently reinforce the posterior wall of the inguinal canal has become popular with Lichtenstein. ${ }^{[16,17]}$ Lichtenstein reported a $0 \%$ recurrence rate in his study (1989) in which 1,000 cases were treated with onlay method, and the study received both negative and positive criticism worldwide. $^{[18]}$ The results obtained by other clinics that apply the Lichtenstein onlay method show consistency with the results of Lichtenstein. ${ }^{[19]}$ Recurrences after inguinal hernia repairs are categorized in two groups as early (mechanic, within first postoperative 2 years) and late (metabolic, many years after the operation) period recurrences. While the tension in the reinforced line is held responsible for the early recurrences, disruptions in the collagen metabolism of transverse fascia and similar structures are held accountable for late recurrences. ${ }^{[20,21]}$ Several complications have been reported in the literature (although not frequently) for Rutkow-Robbins procedures due to less dissection such as orchitis and nerve damage. It is possible disadvantages are pubic recurrence because of applying a graft that does not run over the pubis and problems about reinforcement of the posterior wall due to shrinkage of the unsuturedonlay graft. In the present study, hematoma was observed in the patients as an early complication. No other early period complications were found. Hematoma showed the highest incidence in the Rutkow-Robbins group and the lowest in the Lichtenstein group. We believe that the reason behind that significant difference was the higher amount of drain usage among patients of Lichtenstein group. The most common complication in the late period follow-up of the patients was numbness in the surgical incision site and medial portion of the thigh. Isemeret. al. determined the incidence of numbness in the thigh area as $2.4 \%$ after Rutkow-Robbins operation. ${ }^{[22]}$ Forte et al. conducted a study and following Lichtenstein operation, the incidence of numbness in the thigh area was found to be $4.3 \% .{ }^{[23]}$ In our series, $18(18.9 \%)$ patients showed this complication in total. $5(5.3 \%)$ patients in the Lichtenstein group displayed this complication, whereas seven $(7.4 \%)$ and six $(6.3 \%)$ patients showed it in the Rutkow-Robbins and Gilbert groups, respectively. However, no significant difference was found between the groups. As known, the length of operation depends on many factors such as surgeon's experience, obesity, and use of premade mesh. Therefore, various studies report different operation lengths. While Zeybek et al. report the mean length of operation as $48 \mathrm{~min}$, Karatepe et al. report that length as 50 min. ${ }^{[24,25]}$ However, Janu P.G. et al. performed a study by applying Lichtenstein method and found the mean operation length as $111 \pm 2 \mathrm{~min}$. Isemer et al. conducted Rutkow-Robbins operations in which the mean operation length was $37.8 \pm 15.85$ min. ${ }^{[21,22]}$ Turculet et al. carried out Gilbert double layer operations among which the mean operation length was $65 \mathrm{~min} .{ }^{[26]}$ In this study, our results were consistent with the above literature. The operation length of Gilbert group was found to be longer than those of Rutkow-Robbins and Lichtenstein groups. However, the mean length in Rutkow-Robbins group was lower than that of Lichtenstein group. We believe that higher BMI index of Lichtenstein group may be the reason behind this difference. Gilbert double layer repair differs from the other two techniques with longer operation length and higher intraoperative pain in operations under local anesthesia. ${ }^{\text {[27] }}$ In light of the results of our study that includes a limited number of cases, we believe that spinal anesthesia may be a better choice instead of local anesthesia in Gilbert double layer operations. However, patients subjected to Lichtenstein repair under local anesthesia are reported to suffer less postoperative pain and earlier mobilization. ${ }^{[28]}$ Regarding length of hospital stay, C. S. Huang et al. conducted a study and compared the patients treated with Prolene and plug in which the hospital stay was found to be $1.31+1.00$ days for Prolene patients and $1.45 \pm 1.43$ for plug patients. ${ }^{[29]}$ Isemer et al. determined the length of hospital stay as $2.09 \pm$ $1.35 .{ }^{[22]}$ In the present study, our results showed consistency with the above literature. Though no difference was observed between the three groups, but the time required to return to work have been found to be longer in our study than in previous studies.Isemer et al. found the time required to return to work as $15.3 \pm 12.42$ days in their study. ${ }^{[25]}$ In a study conducted by Sven Bringman et al., it was 16.5 days in the group treated with Prolene, whereas 16 days in the Vypro group. ${ }^{[30]}$ Return to work takes longer in our country due to sociocultural reasons. In the past, postoperative pain following tension repairs was an important and a frequently encountered problem. Particularly after tension-free operations performed with mesh, postoperative pain, return to normal activity, and chronic pain incidence have been found to display decreases. ${ }^{[31]}$ While E. Prieto-Díaz- Chávez et al. reported more frequent and prolonged analgesic usage in the conventional hernioplasty than in tension-free operations, on the contrary, another study underscored the absence of difference between the aforementioned two groups. ${ }^{[32,33]}$ The factors leading to postoperative pain after inguinal hernia repair have been investigated in the previous studies. It is commonly encountered as a result of the nerve entrapment caused by the mesh and is observed in $13 \%$ of the patients. Ilioinguinal nerve entrapment causes pain in the hernia region and scrotum. ${ }^{[34]}$ In the current study, according to the results based on visual analogue scale, there was no statistically significant difference between the three groups at days 1,7 , and 30 with regard to postoperative pain. So these days in the era of laparoscopic surgeries, lots of work 
and studies are being conducted on the various laparoscopic techniques of hernioplasties.

\section{Conclusion}

In conclusion, after studying the repair of inguinal hernia in its various aspects with comparative study of three different techniques of Rutkow-Robbins Repair, Gilbert double Repair and Lichtenstein operation. These findings suggest that the Lichtenstein operation is more advantageous than others due to its lesser hospitalization time, lower complication rate and early resumption of daily activities. Therefore, Lichtenstein technique is recognized as the most advantageous method in inguinal hernia repairs. We believe that this conclusion will be solidified by future studies including larger series.

\section{References}

1. Amid P, Shulman AG, Lichtenstein I. The Lichtenstein open tensionfree hernioplasty. In: Arregui ME, Nagan RF. eds. Inguinal hernia. Advances or controversies? Oxford \&N. York: Radcliffe Medical Press; 1994. P. 185-190.

2. McVay CB, Savage LE. Etiology of femoral hernia. Ann Surg. 1961 Dec; 154 (Suppl 6):25-32.

3. Paajanen $\mathrm{H}$ (2007) A single-surgeon randomized trial comparing three composite meshes on chronic pain after Lichtenstein hernia repair in local anesthesia. Hernia 11:335-339.

4. Rutkow IM (1998) Epidemiologic, economic and sociologic aspects of hernia surgery in the United States in the 1990's. SurgClin North Am 78:941-951.

5. Abrahamson J (1998) Etiology and pathophysiology of primary and recurrent groin hernia formation. SurgClin North Am 78:953-972.

6. Schumpelick V, Treutner KH, Arlt G (1994) Inguinal hernia repair in adults. Lancet 344:375-379.

7. Rutkow IM, Robbins AW (1993) "Tension-free" inguinal herniorraphy: a preliminary report on the "mesh-plug" technique. Surgery 114:3-8.

8. Gilbert AI, Graham MF, Voigt WJ (1999) A bilayer patch device for inguinal hernia repair. Hernia 3:161-166.

9. Milic DJ, Pejic MA. Tension-free procedures in the treatment of groin hernias. SrpskiArhivZaCelokupnoLekarstvo. 2003;131(1-2):82-91.

10. Read RC (1996) Hernia. In: Zuidema GD (ed) Shackelford's surgery of the alimentary tract, vol: 5.WB Saunders, Philadelphia, pp 93-226, Stedman's medical dictionary 1982.

11. Bendavid R (1989) New techniques in hernia repair. World J Surg 13:522-531.

12. Stoppa RE, Diarra B, Mertl P (1997) The retroperitoneal spermatic sheath: an anatomic structure of surgical interest. Hernia 1:55-59.

13. Than VK, Putz T, Rohde H (1992) A randomized controlled trial for inguinal hernia repair to compare the Shouldice and the BassiniKirshner operation. IntSurg 77:235-237.

14. Panos RG, Beck DE,Maresh JE, Harford FJ (1992) Preliminary results of a prospective randomized study of Cooper's ligament versus Shouldiceherniography technique. SurgGynecolObstet 175:315-319.

15. Shulman AG, Amid PK, Lichtenstein IL (1995) A survey of nonexpertsurgeons using the open tension-free mesh patch repair for primary inguinal hernias. IntSurg 80:35-36.

16. Lichtenstein IL, Schulman AG, Amid PK, Montllor MM (1989) The tension-free hernioplasty. Am J Surg 157:188-193.

17. Bailey IS, Karran SE, Toyn K, Brough P, Ranaboldo C, Karrn SJ (1992) Community surveillance of complications after hernia surgery. BMJ 304:469-471.

18. Lichtenstein IL, Shulman AG, Amid PK (1993) The cause, prevention, and treatment of recurrent groin hernia. SurgClin North Am 73:529544.

19. Nyhus LM (1993) Individualization of hernia repair: a new era Surgery 114:1-2.

20. Rutkow IM, Robbins AW. The mesh plug technique for recurrent groin herniorraphy: an nine-year experience of 407 repairs. Surgery. 1998;124:844-847.

21. Janu PG, Sellers KD, Mangiante EC. Mesh inguinal herniorraphy: a ten year review. Am Surg. 1997;63:1065-1071.

22. Isemer FE, Dathe V, Peschka B, Heinze R, Radke A. RutkowPerFixplug repair for primary and recurrent inguinal hernias - a prospective study. SurgTechnol Int. 2004;12:129-136.

23. Forte A, D'Urso A, Gallinaro LS, Lo Storto G, Bosco MR, Vietri F, Beltrami V. Complications of inguinal hernia repair. G Chir. 2002;23:88-92.

24. Zeybek N, Tas H, Peker Y, Yildiz F, Akdeniz A, Tufan T. Comparison of modified darn repair and Lichtenstein repair of primary inguinal hernias. J Surg Res. 2008;146:225-229.

25. Karatepe O, Adas G, Battal M, Gulcicek OB, Polat Y, Altiok M, Karahan S. The comparison of preperitoneal and Lichtenstein repair for incarcerated groin hernias: a randomised controlled trial. Int J Surg. 2008;6:189-192.

26. Turculet C, Feodor T, Dinescu G, Petrică R, Rădulescu S, Beuran M Bi-layer hernioplasty in day surgery. Chirurgia (Bucur) 2007;102:433438.

27. vanVeen RN, Mahabier C, Dawson I, Hop WC, Kok NF, Lange JF, Jeekel J. Spinal or local anesthesia in Lichtenstein hernia repair: a randomized controlled trial. Ann Surg. 2008;247:428-433.

28. Gultekin FA, Kuruahvecioglu O, Karamercan A, Ege B, Ersoy E, Tatlicioglu E. A prospective comparison of local and spinal anesthesia for inguinal hernia repair. Hernia. 2007;11:153-156.

29. Huang CS, Huang CC, Lien HH. Prolene hernia system compared with mesh plug technique: a prospective study of short- to mid-term outcomes in primary groin hernia repair. Hernia. 2005;9:167-171.

30. Bringman S, Heikkinen TJ, Wollert S, Osterberg J, Smedberg S, Granlund H, Ramel S, Fellander G, Anderberg B. Early results of a single-blinded, randomized, controlled, Internet-based multicenter trial comparing Prolene and Vypro II mesh in Lichtenstein hernioplasty. Hernia. 2004;8:127-134.

31. Stephenson BM. Complications of open groin hernia repair. SurgClin North Am. 2003;83:1255-1278.

32. Prieto-Díaz-Chávez E, Medina-Chávez JL, González-Ojeda A, CollCárdenas R, Uribarren-Berrueta O, Trujillo-Hernández B, Vásquez C. Tension-free hernioplasty versus conventional hernioplasty for inguinal hernia repair. . Surg Today. 2005;35:1047-1053.

33. Vrijland WW, van den Tol MP, Luijendijk RW, Hop WC, Busschbach JJ, de Lange DC, et al. Randomized clinical trial of non-mesh versus mesh repair of primary inguinal hernia. Br J Surg. 2002;89:293-297.

34. Ziprin P, Williams P, Foster ME. External oblique aponeurosis nerve entrapment as a cause of groin pain in the athlete. $\mathrm{Br} \mathrm{J}$ Surg. 1999;80:566-568

Copyright: (C) the author(s), 2019. It is an open-access article distributed under the terms of the Creative Commons Attribution License (CC BY 4.0), which permits authors to retain ownership of the copyright for their content, and allow anyone to download, reuse, reprint, modify, distribute and/or copy the content as long as the original authors and source are cited.

How to cite this article: Gupta KP, Singh DP, Hanif, Shahnawaz. Gilbert-Rutkow Mesh Plug Repair of Inguinal Hernia: A Teaching Hospital Based Study.Acad. J Surg.2019;2(1):20-23.

DOI: dx.doi.org/10.21276/ajs.2019.2.1.7

Source of Support: Nil, Conflict of Interest: None declared 